\title{
Application and Research of Blended Teaching Model in Programming Courses* --- Android Application Development Course as an Example
}

\author{
Yong-fei Ye ${ }^{1}$, Ming-he Liu ${ }^{2}$, Xiao Zhang ${ }^{1 *}$, Xing-hua Sun ${ }^{1}$, Nai-di Liu ${ }^{1}$ \\ ${ }^{1}$ School of Information Science and Engineering, Hebei North University, Zhangjiakou, Hebei Province, China \\ ${ }^{2}$ School of Economics and Management, Hebei North University, Zhangjiakou, Hebei Province, China \\ yeyongfei005@126.com,minghe_liu@126.com,780117251@qq.com
}

\begin{abstract}
Big-data era brings forward new requirements of information technology talents. Adapting to this change, we need to break through the limitations of traditional teaching model and take advantage of network teaching platform in programming courses. By introducing blended teaching model, restructure the "teaching" and "learning" and construct an information-teaching environment aimed to improve the students' practical ability and innovative thinking.

Taking an example of Android application development course, based on students' online learning statistics, we proves the feasibility of the implementation of blended teaching model, and provide the reference for other programming courses.

Index Terms - Blended Teaching Model; Network Teaching Platform; Flipped Classroom; Programming Courses; Android Application Development
\end{abstract}

\section{Introduction}

In the contemporary society, communication system developed and billions of devices equipped with Android operating system play an important role in the process of social informatization. The development of Android application software has broad market prospects. "Android application development" is a required program design subjects for electronic information students in our University; the main content involves application software developing based on Android platform, regarding practice as the main foundation.

With the rapid development of information technology, advanced teaching aids applied to teaching classroom gradually, especially online classroom exhibits more advantage than others. Breaking through the limitation of the traditional teaching model, we build a blended teaching model by combing the face-to-face teaching and online classroom teaching. In such complementary informatization teaching environment, the "teaching" and "learning" are restructured to improve the students' practical and innovative thinking ability, and enhance teaching effect [1-3]. Considering the characteristics of "Android application development" course, the blended learning mode is more appropriate to it. Based on Blackboard network-teaching platform, we built the reasonable teaching environment. By learning data analysis, we can see the effect of student learning has improved significantly; it also demonstrated the feasibility of the implementation of blended teaching model in Computer programming courses.

\section{Building Blended Teaching Model}

The specific teaching of "Android application development" is composed of the following parts.

\section{A. Planning the Online Classroom Framework}

On Blackboard network teaching platform, modular deployment "Android Application Development" course. Knowledge that students need to master according to the curriculum requirements is distributed into each module. Abide with the laws of human cognition, the learning objectives, learning syllabus, online learning, homework, teaching cases and experiments corner four modules are built in the course.

In the learning objectives module, knowledge of every chapter is listed in accordance with the Bloom's taxonomy of educational objectives ; in the learning syllabus module, students could learn the major contents of every unit and jump to online learning module directly; all teaching videos for every chapter are uploaded into the online learning module, the related link of teaching PPT and homework also be set here; the teaching cases module consists all complete codes of each teaching example that can be downloaded to their own computers by the students for detailed study and imitation learning; the experiments corner module provides students with experimental guide books and set the storage folder for uploading source experiment codes. By this way, students in the learning process have clear thinking and form "Learning Target -Knowledge Framework - Online Learning Consolidate Knowledge " mainline.

Reasonable curriculum planning has significant meaning for improving the teaching effect, establishing function relatively independent but integration framework is necessary.

\section{B. Making Full Use of Teaching Video}

Research shows that each student pays attention to the video for up to ten minutes, so short teaching video is necessary. Our course teaching video recording based on

\footnotetext{
* This work is partially Supported by the Social Science Research Project of Hebei North University Grant \#S201412) and Instruction plan of Hebei Province Department of Science and Technology Grant \#15217747D and Research and Practice of Hebei Province Higher Education Teaching Reform Project Grant \#2015GJJG138 to Ye Yongfei. *Corresponding author
} 
knowledge units, and strives to attract the attention of students to achieve good teaching effect. The video length will lasted in about 10 minutes, about ten megabytes, MP4 format.

Teaching video is mainly used for students to preview or review the knowledge points. In the teaching process, teachers should position himself in the learning guide, rather than the information transmission. Encourage students to watch the video in question before class and bring doubtful records to class communicating with teachers or classmates, thus can avoid the defect of students cannot record the knowledge individually in limited face-to-face teaching time. The knowledge that cannot be digested in the class can be accomplished by watching teaching videos repeatedly after school.

For example, we adopted the "flipped classroom" mode to organize "building Android development environment " in the course. Asked students to watch the video on the network platform and complete the corresponding task before class, then records problems encountered down to class. By the way of group collaboration, we completed this task better, more than $80 \%$ members to complete the task before class.

Each group leader showed the achievement and those students who didn't finish the task displayed the problems encountered in the class. Teacher carried on the analysis and specified the guider for them. After a week, everyone has successfully built the development environment, by which increasing the learning achievement and experience the fun of self-study, which laid a solid foundation for future learning. The learning process effective tracking and monitoring the teaching extends beyond the classroom.

According to the present teaching mode to achieve the learning process for students effective tracking and monitoring the teaching extends beyond the classroom.

The result of test completion by everyone has shown that has understood the knowledge and mastered operating skills. The present teaching mode realizes the tracking and monitoring of study process effectively and extends the teaching outside of the classroom.

Teachers should use the teaching video to make teaching reflection. In the teaching process, watching the video repeatedly to leak filled, and strive to achieve the goal of teaching successfully.

Making full use of teaching video can enhance the learning effective. Because of the course contents based programming, when recording videos, teacher should input program and explain it at the same time. By using the teaching video to make teaching reflection, watching the video repeatedly to leak filled, and strive to achieve the goal of teaching successfully.

In the process of watching the video, students can operate computers to simulate, following the teacher's guide to debug their programs. This operation can avoid the phenomenon of remote "appreciate" the program code and understand the knowledge in the classroom but forgotten after school. Close watching video narrows the distance between students and teachers, and makes students feel in equal status with the teacher, no longer like a command and the command position in class teaching, decreasing students' psychological pressure. Learning in a relatively relaxed environment, and learn to control their own progress is truly individualized.

In the network classroom, exercises should be done after watching video and class, used to consolidate knowledge.

\section{Interaction in Network Classroom Teaching}

In order to keep abreast of students' learning attitude timely and improve their enthusiasm, online teaching interactive is also essential. On Blackboard8, lots tools can be used to communicate, such as course discussion boards, group discussion boards, notification, e-mail and collaboration.

Figure 1 is a discussion board in the situation of students' speaking in the curriculum, in which more topics related to study. Speaking reflects the situation of students learning attitude and motivation. Some students did very well, to share their acquired knowledge skills and help others actively. But there are also individual students never have spoken, whose attitude slack, losing confidence in learning, becoming the focus of helping object. In the teaching process, teachers often visit this section to view the speech of students, identify problems and help to resolve timely. Through this interaction, the students can understand the teacher's attention, and to learn more confidence. This communication, which breaking time and space constraints and the using of text on some issues are described in more accurate than oral, can give you space to think with, therefore avoiding face-to-face embarrassment when the exchange ocuus.

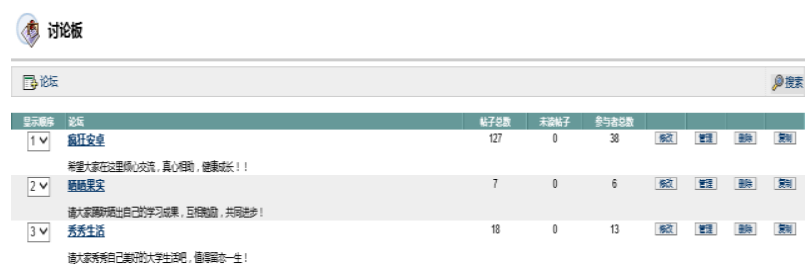

Fig. 1 Summary of posts in course discussion board

The notification as a communication tool is often used in online interactive process effectively. In the curriculum design process, notification will be as access entry of the course, mainly for the releasing of weekly learning tasks, and sometimes publishing the notification of created test newly. Real-time notifications serve as a reminder, expediter, so that students can keep abreast of their learning tasks and rationalize learning progress. The function of e-mail provided is used to bulk mail, facilitating the circulation of information. We can also use collaboration to create a virtual classroom, where you can exchange instantly.

All of the above communication tools for teaching using co-ordinate can play a good supporting role. Education is interaction of teaching and learning, is coordination of teacher and student, which requires real-time and accurate exchange of information, all integration opportunities for communication are in need. 


\section{Group Cooperative Learning}

Group cooperative learning helps to cultivate team spirit and independent thinking habits, highlight the dominant position of students, strengthen the students' learning responsibility, improve students' innovative creative thinking ability. According to the "group heterogeneity, inter group homogeneity" principle, the students are divided by six members of each group. Group leader shall be borne by the one who has outstanding achievement and responsibility to manage the group. Students interact with each other to complete the assigned tasks, learning from each other. Fig. 2 shows part of the assigned groups, which names are free.

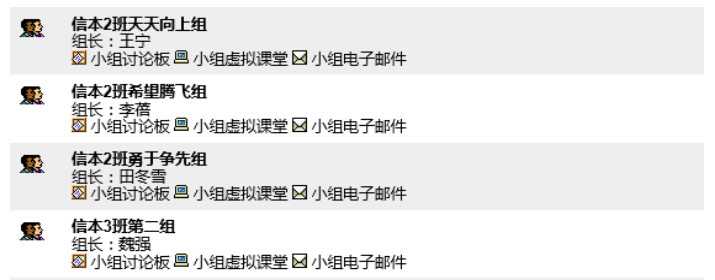

Fig. 2 Part of the assigned groups

The tasks of the course should be completed by group cooperation. Especially in the course design, from the topic, document writing, and code written to the program testing, each member has a clear division of labor, but also cooperation. When showing works, each group tries to show the best side and acting in harmony.

Group cooperation use the board and other communication tools to make group members in a relaxed, self-learning environment, and reducing their loneliness. Students will make significant progress in this environment, which will help to produce innovation.

\section{E. Evaluation System of Teaching Effect}

Teaching evaluation can help teachers keep abreast the situation of students' knowledge to have and adjust the teaching arrangements according to the evaluation results, that is an important link in the teaching work [4]. The course uses a variety of teaching evaluation methods for monitoring student learning, such as curriculum resources access, on-line test, offline operations and works display, etc.

Figure 3 is a cumulative charts basis students' access data to the course in a week throughout the semester. By comparison figure data, we can see a significant increase visited on Wednesday, before and after the one-day visiting is relatively high. The analysis revealed that theoretical teaching is scheduled on Tuesday and experiment teaching on Wednesday, so students will submit homework in time, review and preview adjacent, especially on Wednesday, students are required to submit the test report through the network platform, so visits highest. These data illustrate, task-driven pedagogy usefulness [5]. In the driving task, the students' enthusiasm greatly improved. For each experiment, the students are able to complete, and in accordance with the requirements of upload timely, thus increasing the learning enthusiasm.

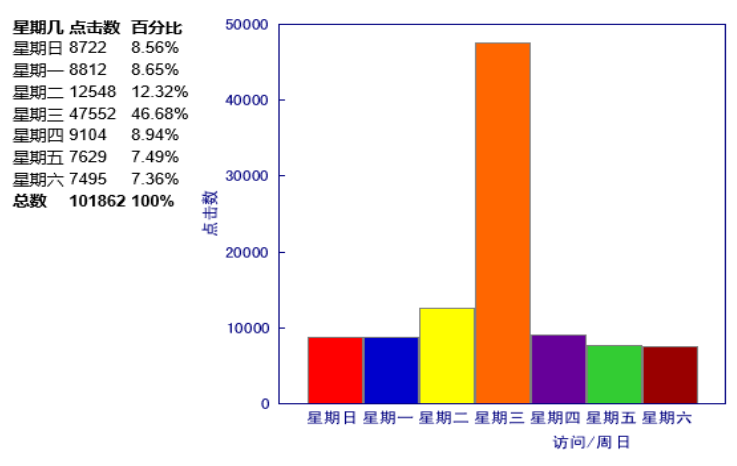

Fig. 3 Student visits course chart in a week

Students' visits of course are also an important reference value as an evaluation reference items besides submitting the job. If you find that some students' visits lower, then you should focus on and communication with the students timely, to find the cause in the learning process. Analysis the students whether they do not understand, or lack of interest in learning, and then resolve it. Figure 4 captures some students' statistical data of the course visits in September, from the figure, there are views of a small part of students' access is less than 100, then these students will become the conversation object.

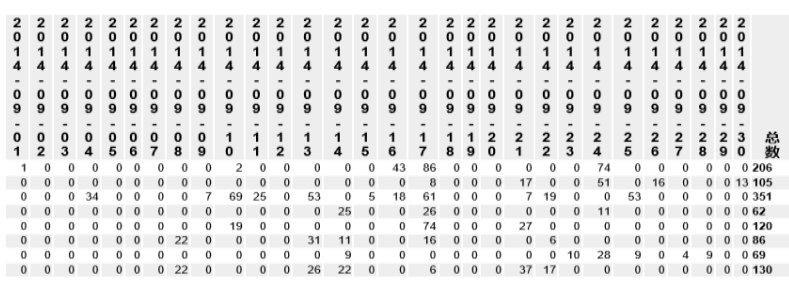

Fig. 4 Students' visits in september

Figure 5 is a chart of students' regional visits in the course. Seen from the figure, the majority visits concentrated in the content area, for the region mainly contain curriculum learning resources; but the group area visited is small, that indicating students do not take advantage of the regional group discussions to promote learning, which suggests the direction we should be teaching this as a guide for students to learn to strive teamwork, collaborative learning.

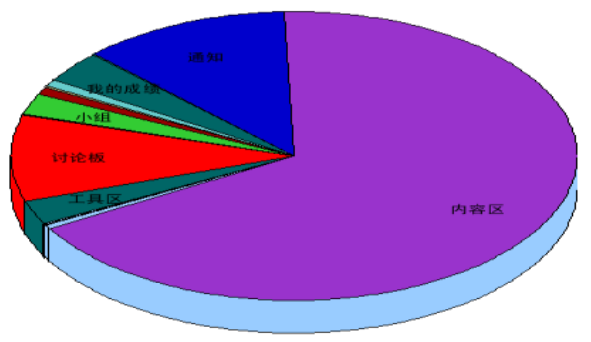

Fig. 5 Students' regional visits chart

Figure 6 shows part score data of the students in a variety of tests and homework in the learning process. In the table there are blank areas, because that the students did not 
participate in the test or not to submit assignments. Through the statistics to analysis students' mastery of knowledge, such as the correct rate, scoring rate, then we can supplementary knowledge for students in the class. From each experimental results presented by students, we can find that students obtain strong practical ability and find the learning objectives; all these have good implications for their later study and work.

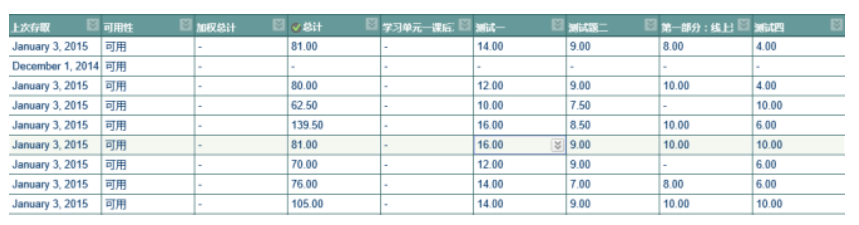

Fig. 6 Students' score table

The degree of perfection of teaching evaluation system has significant influence on the teaching effectiveness. Teaching evaluation system design should consider all factors, and then design right amount appropriate tests, homework and discussion topics combining with the knowledge. Combined in various ways, and improve the students' interest in learning constantly, strengthen the learning effect, so that they form a good habit of autonomous learning, active learning.

\section{F. Curriculum Assessment Programs}

Considering the strong practical features of the course, using computer-based test approach as final exam. We created single choice, true or false, simple answer questions and programming design four types databases. Test papers are composited random, differ from one to one. The objective questions are automatic marked by the system; teacher should handily mark the subjective.

Tracking the students' learning process and combining all factors to set the weight of every test (including the regular test, homework and participation, etc.) to produce the final evaluation. The evaluation is more objective than ever. The final results show that the implementation of the curriculum mobilizes the enthusiasm of the students effectively and complete the teaching task successful. Students programming abilities are enhanced, team cooperation can submit entries, all these will form a virtuous cycle of learning process.

\section{G. Course Archives}

At the end of the term, the archives must be done carefully. We should save all relative recourses, such as teaching recourses, students' learning process record, the test results, homework and discussion opinions. Analysis these materials aimed to improve the quality of teaching in the future. The teaching achievements play an important guiding role for the teaching.

Review the whole teaching process, there are many places that need to be improved.

\section{Conclusion}

Practice has proved that the blended teaching model is suitable for the course. The amount of teaching resources is about two times of the traditional teaching model. The teaching effect is improved obviously and the main benefit lies in improving the students' learning enthusiasm and pleasure greatly. "A handy tool makes a handy man", person's energy is limited, with favorable tools can extend human capabilities. Network teaching platform as a necessary complement to traditional classroom teaching plays an important role in teaching.

Through practice, we can see that the programming course is suitable for adopting the blended teaching model. Restructuring the "teaching" and "learning", breaking through the traditional teaching bottleneck, the teaching effect will be improved obviously.

\section{References}

[1] WANG Qiong, FENG Fei, LIU Ling etc. Mixed Success Teaching Manual of Blended Teaching Model. Beijing: Peking University Press, 2013:8-12.

[2] Li Jinxia, Research on Net Class Teaching Model of College "Program Design". Hebei University, 2005-06.

[3] ZHU Hong-fei, ZOU Qi-ming, CHEN Zhang-jin. To Discuss Application of Research-Based Teaching Mode In Programming Design Course. COMPUTER PROGRAMMING SKILLS \& MAINTENANCE, 2012, 14:147-149.

[4] HA Wei-tao. Construction and Realization of Evaluation Model of the Learning Network. SCIENCE INFORMATION,2010,(1):275- 276.

[5] ZENG Xiang-guang. Study on Application of Task-Driven Teaching Method in "Flipped Classroom". CHINA ADULT EDUCATION, 2014, (7):130-132. 